\title{
DISCUTINDO A AVALIAÇÃO DE UM PROGRAMA DE CAPACITAÇÃO PARA ENFERMEIROS
}

\author{
DISCUSSING A PROGRAM FOR TEACHING NURSES \\ DISCUTIENDO UN PROGRAMA DE CAPACITACIÓN PARA ENFERMERAS
}

Cristina Melo ${ }^{1}$

Norma Fagundes ${ }^{2}$

\begin{abstract}
RESUMO: o artigo discute a pertinência de atividades de treinamento desenvolvidas no setor saúde, com base em uma experiência concreta avaliada pelas autoras. Aponta e discute os elementos considerados relevantes para a introdução de treinamentos para trabalhadores da saúde que pretendam contribuir no desenvolvimento de competências e que ultrapassem a mera dimensāo de adestramento para tarefas especificas. Distingue as dificuldades existentes tanto na utilizaçāo do treinamento como parte do processo de desenvolvimento de pessoas, bem como as dificuldades no processo de transferência dos conhecimentos adquiridos no processo de trabalho.
\end{abstract}

PALAVRAS-CHAVE: treinamento e desenvolvimento em saúde, gestăo de competências, transferência do treinamento, avaliação do treinamento.

\section{INTRODUÇĀO}

Este artigo pretende discutir alguns aspectos do treinamento de trabalhadores da saúde, refletindo uma experiência de avaliar um treinamento especifico para enfermeiras da rede pública de serviços de saúde. $O$ treinamento originou-se de uma proposta elaborada pelo Ministério da Saúde/Secretaria de Assistência à Saúde/Programa Nacional de DST/AIDS (1997) constante em um manual especifico que inicialmente selecionou e treinou enfermeiras de serviços e professoras de escolas de enfermagem de várias cidades do pais para atuarem como instrutoras deste processo.

Deste modo foi realizado no Estado da Bahia o treinamento de enfermeiras para a prevenção do HIV e assistência às pessoas portadoras do HIVIAIDS, cuja clientela seria enfermeiras da rede pública de serviços de saúde localizados na capital e no interior do estado.

A ênfase nas reflexōes aqui expressadas está na discussão do modo como se processam os treinamentos no setor saúde, geralmente desenhados e implementados centralizadamente e de modo esporádico, sem fazer parte de um plano estratégico de desenvolvimento e treinamento de pessoal das instituições.

Alèm disso, alguns aspectos centrais do processo de avaliação desenvolvido na experiência concreta referida serão considerados na análise, visando contribuir para sua implementaçăo, principalmente quanto a treinamentos direcionados a enfermeiras.

Neste artigo não entraremos na discussão que a utilização de termos como "treinamento", "capacitação", "reciclagem", etc. Em gerado quando referentes a processos educativos de pessoal na área de saúde.

' Professora Assistente do Departamento de Enfermagem Comunitária da Escola de Enfermagem da Universidade Federal da Bahia, Mestre em Saúde Comunitária/UFBA.

2 Professora Assistente do Departamento de Enfermagem Comunitária da Escola de Enfermagem da Universidade Federal da Bahia, Mestre em Saúde Comunitária/UFBA. 


\section{TREINAMENTO: PORQUE FAZER ESTA ESCOLHA?}

Quando se fala em gestão de pessoal, pensa-se logo em treinamento. As atividades de treinamento sempre têm tido um papel prioritário nas instituiçōes públicas de saúde. De panacéia para todos os males identificados ou não, o treinamento passou a ter também o crédito de permitir o gasto rápido de recursos, quase sempre em exercicios findos, principalmente os atrelados a projetos e programas especiais de saúde, na maioria das vezes com um financiador externo. Ou então é usado como o sinal aparente de que a organização "importa-se com seu servidor".

No entanto, hoje fala-se muito em treinamento e desenvolvimento, mas o primeiro item é o mais aparente e considerado também o "mais fácil" de ser avaliado.

A gestão de pessoas não pode mais ter como pressuposto a necessidade de adestrá-las para a execução de funções e tarefas. Sabe-se que cada vez mais, a maior parte das tarefas ou as tarefas mais importantes são delegadas aos funcionários com mais alto desempenho, deixando subaproveitados os demais (Riehl, 1998).

Em especial, poucas ou quase nenhuma das organizaçőes públicas de saúde saberiam dizer quanto, em quê e qual a avaliação dos treinamentos promovidos para seus servidores.

Mesmo programas que buscam, nas empresas, combinar as capacidades de cada funcionário com as tarefas que melhor podem desempenhar, têm tido um caráter muito mais de adestramento visando uma maior produtividade do que um desenvolvimento permanente do ser humano inserido no mundo do trabalho.

Broad; Newstrom (1995) discutindo a transferência do treinamento nos Estados Unidos, identificam que quando bem definidos e realizados, isto é, - quando os problemas sobre os quaís se quer interferir têm relação direta com a introdução ou implementação de novos conhecimentos e habilidades - , apenas $50 \%$ do treinamento pode vir a ser aplicado um ano depois do seu término, devido a múltiplos fatores, dentre eles os relacionados à adequação dos conteúdos e as perspectivas internas ao trabalho.

Por outro lado, as barreiras para o desenvolvimento das habilidades e conhecimentos adquiridos nos treinamentos estão diretamente relacionados com atitudes dos gestores dos serviços ou de aspectos estruturais da organização.

Isto significa que a opção pelo desenvolvimento de treinamentos deve buscar atender a alguns aspectos fundamentais, que relacionaremos a título de ilustração:

- a decisão sobre qual treinamento e quem deve participar do treinamento deve ser compartilhada por gestores e órgão de recursos humanos ou pessoa responsável por desenvolvimento e treinamento na instituição;

- muitos problemas de desempenho das pessoas não podem ser resolvidos por treinamentos;

- as atividades de treinamento devem ser consideradas como estratégicas para a organização;

- as atividades de treinamento e desenvolvimento podem ter um grande impacto na produtividade e competitividade, caso bem definidas e implementadas.

O que se avalia, em particular nas instituições públicas de saúde, é que todos os aspectos acima destacados ainda são, em sua maioria, ignorados. Além do mais, as atividades de treinamento não seguem os passos do seu processo, isto é, análise de necessidades e planejamento, modelo de desenvolvimento baseado em competências; planejamento adequado do conteúdo; desenho e desenvolvimento da intervenção de aprendizagem e avaliação continuada (Broad; Newstrom, 1995). Consequentemente, os conhecimentos e habilidades porventura adquiridos não são transferidos para a organização, resultando o treinamento em um desperdicio de recursos, limitado quando muito a proporcionar beneficios pessoais (quando há) aos treinandos. 
O que se tem observado é que a ênfase neste tipo de capacitação não tem contribuido para que os próprios sujeitos das práticas reconstruam o seu trabalho. Permanece assim uma contradição clara entre os programas de capacitação centralizados e distantes da realidade dos serviços e as demandas do processo de municipalização e descentralização que requerem a ampliação da capacidade de decisão local e novas formas de relação com a clientela. Onde os processos de capacitação devam ser colocados como parte do processo de gestão do trabalho coletivo nos serviços, voltados à construção de um novo contrato ético e politico dos profissionais com a população (Ribeiro; Motta, 1996).

\section{DISCUTINDO O TREINAMENTO DE ENFERMEIRAS E A AVALIAÇÃO}

Os comentários desenvolvidos têm como base o treinamento de três grupos de enfermeiras, realizados no final de 1997 e inicio de 1998 pela Secretaria de Sáude do Estado da Bahia e Escola de Enfermagem/UFBA.

No projeto inicial, foram elencados pelo Ministério da Sáude (MS) para avaliação do treinamento os seguintes indicadores:

Indicadores de desempenho:

$-\%$ de vagas preenchidas - nos dois primeiros treinamentos o número de vagas oferecidas foi de 25 (vinte e cinco). Após estes dois treinamentos, avaliou-se que para a metodologia participativa adotada no curso, o número de participantes era excessivo e optou-se por diminuir este número para 20 (vinte);

-\% de profissionais que concluiram o treinamento entre os selecionados - o critério adotado para a seleção foi o de indicação pelas instituições envolvidas de técnicos que atuassem ou que tivessem previsão concreta (novos serviços que estivessem sendo implantados) de assistência e/ou prevenção da AIDS.

-número de treinamentos realizados em relação ao previsto - inicialmente foram previsto 6 (seis) treinamentos.

-número de pessoas que obtiveram proficiência antes e após o treinamento - este critério foi previsto inicialmente através da aplicação de pré e pós testes de conhecimento, tendo como resultado a média entre estas duas avaliações. Mas, levando-se em consideração os objetivos do treinamento de sensibilizar e não apenas informar e desenvolver habilidades técnicas nas enfermeiras e, também, diante dos tabus e preconceitos existentes em relação à AIDS, bem como de uma postura normativa e autoritária, comum entre os profissionais de saúde, optou-se por realizar uma avaliação com outras características.

Assim, a avaliação realizada não teve como foco o grau de informação técnico-cientificas absorvidos, mas principalmente coletar e avaliar as opiniões e percepção das treinandas sobre a capacitação recebida e sobre o tema em questão (a prevenção e assistência às pessoas portadoras do HIVIAIDS).

Deste modo, o objetivo pretendido da avaliação foi o de fornecer uma oportunidade para que as treinandas opinassem em relação às questões acima referidas, como uma forma de oferecer subsidios para o aprimoramento do próprio treinamento no seu decorrer, bem como sobre os que ainda seriam realizados.

- Indicadores de impacto - que visam o acompanhamento dos profissionais treinados em seus locais de trabalho também foram previstos. Estes farão parte de outro momento de avaliação, e não serão aqui considerados. 
Analisando os resultados obtidos seguindo os indicadores definidos pelo MS, nos três cursos foram inscritas 61 (sessenta e uma) enfermeiras, o que corresponde ao preenchimento de $87,1 \%$ das vagas oferecidas. Concluiram 59 (cinqüenta e nove), o que significa $96,7 \%$ das inscritas.

A primeira parte do instrumento utilizado na avaliação procurou levantar informações que permitissem:

a) caracterizar o perfil das treinandas, bem como das atividades realizadas pelas mesmas;

b) conhecimento prévio sobre atividades relacionadas com o tema do treinamento;

c) percepções das treinandas sobre portadores do HIVIAIDS.

Aqui vale destacar a primeira observação quanto à seleção das treinandas, que foi realizada pelo local de trabalho das mesmas.

Apenas 34 treinandas $(55,7 \%)$ atuam na área do treinamento. Entre as treinandas que não trabalham com a área, 13 apresentaram perspectivas remotas, ou seja colocaram de forma imprecisa a possibilidade de que em seus locais de trabalho venham a desenvolver açöes na área.

Constata-se que o critério estabelecido pelo MS de dirigir o Treinamento prioritariamente para enfermeiros trabalhando na prevenção e assistência aos portadores do HIVIAIDS ou em perspectiva de vir a trabalhar, não foi muito bem observado. Este é um requisito que não só torna inadequado o treinamento realizado como contribui para este se constituir em uma via de desperdicio de recursos, o que se torna ainda mais grave se considerarmos a escassez de recursos públicos na saúde. Esta prática é habitual nas instituições públicas de saúde e se constitui em um elemento que impede, dentre outros fatores, a transferência do treinamento para a atividade desenvolvida pelo treinando. Ainda que sejam desconhecidas pesquisas neste setor, no Brasil, é necessário reforçar a necessidade urgente de mudar esta política interna às instituições de saúde, como requisito fundamental para não só melhor gerir os recursos públicos, como efetivamente gerir pessoas com base nas suas competências, que devem ser aprimoradas para responder as necessidades de reorganização e qualidade dos serviços e açöes de saúde hoje prestados à população brasileira.

Quanto a análise da percepção das treinandas em relação às pessoas portadoras do HIVIAIDS, foram registradas as expressōes das mesmas antes do inicio e após o término do treinamento. Os comentários solicitados deveriam se referir a duas afirmativas utilizadas no manual do treinamento:

"As pessoas com AIDS são culpadas por terem contraido esta doença".

"Possiveis influências sócio-culturais que podem expor pessoas ao risco de contrair a infecção pelo HIV na sua cidade".

As opiniões nas duas etapas analisadas (início e final do curso), não apresentam diferenças significativas a registrar.

As treinandas não consideram que as pessoas sejam culpadas por contrair a AIDS, e creditam a epidemia existente à falta de informação e algumas ao descaso das politicas governamentais em relação ao setor saúde.

No entanto, as opiniões revelam quase sempre uma percepção linear e aparentemente ingênua da AIDS e da possibilidade de mudança de conduta das pessoas apenas com informações de como se previne a doença.

Sobre esta crença (da qual não partilhamos), de que maior informação equivale à mudança imediata de hábitos e estilo de vida, chamamos a atenção para o caráter homogeneizador de que se reveste as campanhas educativas, nas quais a população estaria sujeita de forma igual aos riscos, cada grupo populacional teria o seu conjunto de fenômenos biológicos e universais característicos que os conduziria ou não a situações de risco. Acontece "que os obstáculos à prevenção e o grau de exposição à epidemia variam muito de acordo com os individuos e os grupos sócio-culturais a que pertencem. Sem levar isso em conta não temos como fazer uma 
intervenção preventiva eficiente" (Ayres apud Amaral, 1997).

Além destes aspectos, o Betinho aponta o caráter pouco democrático dos meios de comunicação de massa (onde apenas alguns grupos editam a "realidade" do pais) e afirma que "Informar e bem, significa democratizar os conteúdos, apresentar a democracia como centro do próprio processo, dar oportunidades a muitas vozes, abrir o leque das fontes jornalisticas, avançar para um relacionamento onde prevaleçam verdades e não versões, onde o diálogo priorize a maturidade da ética e não as variáveis dos descompromissos e dos factóides. (...) Com certeza é no cotidiano, com a ajuda dos movimentos sociais e da ampliação do diálogo entre os diversos setores e principalmente entre as áreas de Imprensa e Saúde que constituiremos um novo cenário para a comunicação neste país" (Souza, 1996).

$\mathrm{Na}$ avaliaçăo final, o que predominou foram afirmaçōes tais como: "nāo devemos julgar os outros" e "estas pessoas precisam de apoio e não de julgamento". A que se pode atribuir tal fato? Supor que o treinamento, de algum modo, tenha contribuido para reforçar um aspecto mais humanitário na visão do profissional sobre o portador de HIVIAIDS ou apenas interpretar que tal achado reflete a visão religiosa ainda fortemente influente na formação das enfermeiras?

No entanto, este fato ressalta a necessidade de melhor desenhar os conteúdos de treinamentos com esta temática, visando trabalhar esta visão existente entre os profissionais de saúde. Isto porque, na prática, os serviços de saúde e a clientela ressentem-se das atitudes preconceituosas dos profissionais.

Isto é revelado nas opiniōes de algumas treinandas, onde aparecem claramente expressöes de preconceito quanto aos portadores ou doentes pelo HIVIAIDS.

Destacam-se a crença na existência de grupos de risco como homossexuais, prostitutas e usuários de drogas, além de uma excessiva ênfase do controle da epidemia como dependente de atitudes individuais, num processo de "vitimar a vitima". Isso é reforçado pela opinião de cinco treinandas, ao afirmarem categoricamente que quem tem informação e tem a doença são culpados por tê-la adquirido.

Em outras opiniōes registra-se o aspecto da promiscuidade, relacionada ao comportamento do sexo masculino, especialmente no final do curso, no inicio este aspecto da promiscuidade era mais generalizado. A baixa escolaridade, além da falta de informaçāo, foi um fator considerado como facilitador à expansão da epidemia da AIDS. Surgem também expressōes relacionadas a questōes sócio-culturais como "restrições ao uso da camisinha pelos homens", "comportamento machista dos homens", "submissão feminina", além das "festas populares e caracteristicas do Estado" e "ritos e tabus religiosos".

Em relação a avaliação do processo de treinamento os resultados obtidos foram sempre favoráveis, com exceção de comentários no treinamento inicial quanto ao espaço físico designado para a atividade. No entanto, no acompanhamento de algumas atividades do treinamento pelas autoras, o processo não parece ser tão bem aceito ou quase perfeito, constatando-se nestas observaçōes dispersão do grupo, certa resistência em cumprir com as atividades programadas, não cumprimento da pontualidade necessária para o desenvolvimento de atividades coletivas e de interação permanente com a clientela.

\section{CONSIDERAÇŌES FINAIS}

Para que se possa avaliar um treinamento é preciso não só avaliar o seu processo, o que parcialmente foi feito, até porque tratava-se de uma proposta formatada centralizadamente.

O importante em treinamentos é avaliar seus resultados, independentemente do modelo de avaliação que se venha a adotar. Na avaliaçăo de resultados é preciso abordar não apenas o produto do treinamento, bem como o produto da aprendizagem dos novos conhecimentos e habilidades das enfermeiras que deverão estar trabalhando em serviços direcionados para a prevenção e tratamento dos portadores de HIVIAIDS. Outro aspecto relevante da avaliação, que deve ser continuada, diz respeito ao comportamento desenvolvido no local de trabalho e dos resultados do serviço onde atua a profissional treinada. 
Tais informações serão relevantes para retroalimentar novos planos e modelos de treinamentos, que devem ser direcionados para necessidades concretas dos serviços. Ainda que seja realizado com precariedades, tanto metodológicas quanto operacionais, o processo de avaliação permitirá redirecionar recursos e esforços adequadamente, contribuindo também para que o setor público de saúde comece a investir no seu maior capital, o capital humano. Além do que o processo de avaliação permitirá gerir adequadamente os recursos materiais e financeiros e deste modo poderemos afirmar que treinamento pode vir a ser parte da solução para muitos dos problemas identificados nos serviços de saúde. Lembrando sempre que o treinamento é parte da solução, quando novas habilidades e conhecimentos forem parte significativa das causas dos problemas existentes (Broad; Newstrom, 1995). Para que isto aconteça é necessário que a avaliação se torne parte do cotidiano dos serviços.

Recomenda-se, por fim, que ao invés de apenas treinamentos isolados, sejam também realizados programas de educação permanente que privilegie discussão de casos, problemas do serviço, experiências de outros locais e textos de interesse da área. Seja dada também oportunidade aos treinandos de conhecer/observar outros serviços existentes de prevenção e assistência aos portadores do HIVIAIDS. Não apenas outras instituições assistenciais, mas sobretudo ONG's e outras organizações da sociedade como uma forma de trazer novas visőes sobre o problema para as instituições de saúde.

ABSTRACT: This article discusses the property of training activities developed in health sector, based on the author's experiences. It tries to evidence the most important aspects to introduce health workers training getting ahead mere especifical work dimention. It also intends to discuss the importance of this training as a part of the process for people improvement as well as for the knowledge transference process.

KEYWORDS: training and development in health sector, managment, training evaluation, training transfer.

RESUMEN: El articulo discute la pertinencia de las actividade de entrenamiento desarrolladas en el sector de la salud, basado en una experiencia concreta evaluada por las autoras. Discute los elementos considerados importantes para la introducción de entrenamientos de los trabajadores de salud, que contribuyan a su competencia y que ultrapasen la mera dimensión de adiestramiento para tareas especificas. Distingue las dificultades existentes tanto en la utilización del entrenamiento, como en la transferencia de los conocimientos.

PALAVRAS LLAVE: entrenamiento y desarrollo en el sector de la salud, gestión de competencias, transferencia del entrenamiento, evaluación del mismo.

\section{REFERÊNCIAS BIBLIOGRÁFICAS}

AMARAL, M. Camisinha pra que? Revista Caros Amigos, n. 7, São Paulo, 1997.

BROAD, M. L.; NEWSTROM, J. W. Transfer of Training. Action-Packed Strategies to Ensure High

Payoff from Training Investments. Massachusetts: Addison-Wesley Publishing Co, 1995.

DUBOIS, D. Competency-Based Performance Improvement: A Strategy for Organizational Change. HRD Press Inc., 1995.

MINISTÉRIO DA SAÚDE. Secretaria de Assistência à Saúde. Programa Nacional de DST/AIDS. Manual de orientação básica para equipe de enfermagem/prevenção do HIV e assistência à pessoas portadoras do HIV e AIDS. Brasilia (DF), 1997.

RIEHL, H. Gestão baseada nas capacidades. HSM Management, n. 8, 1998.

RIBEIRO, E. C. de O ; MOTTA, J. I. J. Educação permanente como estratégia na reorganizaçăo dos serviços de saúde. Divulgação em Saúde para Debate. n. 12, jul. 1996.

SOUZA, H. J. de. Informaçāo pela informaçāo não basta. In: LOPES, B.; NASCIMENTO, J. (Orgs.). O público que se dane! Rio de Janeiro: Editora Mauá, 1996. 